\title{
The importance of combining of ultrasound and mammography in breast cancer diagnosis
}

\author{
Svjetlana Mujagić ${ }^{1}$, Mensura Burina ${ }^{1}$, Jasminka Mustedanagić-Mujanović ${ }^{2}$, \\ Goran Šarkanović ${ }^{2}$
}

${ }^{1}$ Department of Radiology and Nuclear Medicine

${ }^{2}$ Policlinic of Laboratory Diagnostic of the University Clinical Center Tuzla Tuzla, Bosnia and Herzegovina
Received: 5 April 2011 Accepted: 16 April 2011

Copyright (C) 2011 by Academy of Sciences and Arts of Bosnia and Herzegovina. E-mail for permission to publish: amabih@anubih.ba
Objective. The aim of this study was to analyse individual and combined sensitivity and specificity of ultrasound and mammography in breast cancer diagnosis and emphasize the importance of combining breast imaging modalities. Patients and methods. By means of a cross-sectional study, ultrasound and mammographic examinations of 148 women (mean age $51.6 \pm 10.8$ years) with breast symptoms were analysed. All women underwent surgery and all lesions were examined by histopathology analysis which revealed the presence of 63 breast cancers, and 85 benign lesions. In relation to age, the women were separated in to a group under 50 years and a group 50 years and older. Ultrasound and mammographic findings were classified on the BI-RADS categorical scale of 1-5. Categories 1, 2 and 3 were considered negative, while categories 4 and 5 were positive for cancer. For statistical data processing the McNemar chi-square test for paired proportions was used. The differences on the level of $p<0.05$ were considered statistically significant. Results. In the group under 50 years, the ultrasound sensitivity was significantly higher than the mammographic sensitivity $(p=0.045, \chi 2=4)$, without a statistically significant difference in specificity $(\mathrm{p}=0.24, \chi 2=1.39)$. In the women over 50 , a significant difference between sensitivity of ultrasound and mammography was not proved $\left(\mathrm{p}=0.68, \chi^{2}=0.17\right)$, nor any difference in the specificities ( $\mathrm{p}=0.15, \chi^{2}=2.08$ ). In the group consisting of all patients, the sensitivity of ultrasound was statistically significantly higher in comparison with the sensitivity of mammography $\left(\mathrm{p}=0.04, \chi^{2}=4.27\right)$ with higher specificity $\left(\mathrm{p}=0.04, \chi^{2}=4\right)$. By combining the two methods in all patients sensitivity of $96.8 \%$ was achieved, in patients up to 50 sensitivity was $90.47 \%$ and in patients over 50 , sensitivity was $100 \%$. When the two methods were combined in all patients, a decrease in specificity was noted. Conclusion. The combination of ultrasound and mammography in breast cancer diagnosis achieves high sensitivity and the number of undetected breast cancers is reduced to minimum.

Key words: Breast cancer, Ultrasound, Mammography, Sensitivity, Specificity. 


\section{Introduction}

Breast cancer is the most common malignancy in women (1). After lung cancer, it is the most common cause of death from malignancies that affect the female gender (2) and in many countries is in the first place, so it is known as the leading female cancer (3). Thanks to mammography, breast ultrasound and the appropriate surgical and postoperative treatment, in recent years there has been a trend reducing the breast cancer mortality rate. Mammography is used as a screening method for early detection of breast cancer in women after 40 , in some countries after 50 years of life, while breast ultrasound is the imaging of choice in women under 40 years (1). With an appropriate combination of ultrasound and mammography, the number of undetected breast cancers can be reduced to a minimum.

The aim of this study was to analyse the individual and combined sensitivity and specificity of ultrasound and mammography in breast cancer diagnosis and emphasize the importance of combining of breast imaging modalities.

\section{Patients and methods}

By means of a cross-sectional study, ultrasound and mammographic examinations of 148 women with breast symptoms or positive family history for breast cancer in the period from January 2009 to November 2010 were analysed. All the women underwent surgery and all 148 breast lesions were examined by histopathology analysis. Histopathology results revealed the presence of 63 breast cancers, and 85 benign lesions. Diagnostic imaginings were performed at the Department of Radiology and Nuclear Medicine, surgical treatment at the Department of Surgery, and pathohistological analysis at the Department of Pathology of the Polyclinic for Laboratory Diagnostics of the
University Clinical Centre, Tuzla. The group pattern was made consecutively. In relation to age, the women were separated into two groups, group A: women up to 50 years and group B: women 50 years and older. The breast ultrasound was performed on a "Sonoline G60 S"- Siemens ultrasound machine with $12 \mathrm{MHz}$-linear array transducer and if needed with $7.5 \mathrm{MHz}$-linear array transducer. Mammography was performed by a "Mammomat Nova 3000"-Siemens. Standard mediolateral oblique and craniocaudal views of each breast were taken.

To obtain and read mammography images, cassettes with phosphorus imaging plates (18x24 and $24 \times 30)$, mamma-laser drystar DT-2 films and digitizer type CR 85-X with an NX workstation were used.

The findings were interpreted by two radiologists. Additionally, according to the radiological features of the described pathological changes, ultrasound and mammographic findings were classified on the BIRADS categorical scale of 1-5 (4) as follows:

1. No significant abnormality,

2. Benign finding,

3. Probably benign finding,

4. Suspicious lesions- suspicious abnormality and

5. Highly suggestive of malignancy -malignant lesion.

Categories 1, 2 and 3 were considered negative, while categories 4 and 5 were considered as positive for cancer. To test the overall sensitivity and specificity of the two methods, a positive finding to cancer was considered if only one or both tests were positive, and negative to cancer when both tests had negative findings.

The standard methods of descriptive statistics (mean and standard deviation), standard statistical parameters, and parametric McNemar chi-square test for paired proportions were used for statistical data processing. The sensitivity and specificity of the methods were determined by the $2 \times 2$ table 
diagnostic test. The differences on the level of $p<0.05$ are considered statistically significant.

\section{Results}

The study included 148 patients, 63 patients with breast cancer and 85 patients with benign lesions. The mean age of all the patients was $51.6 \pm 10.8$ years, ranging from 19 to 79 years. The mean age of patients with breast cancer was $55.4 \pm 11.4$, ranging from 26 to 79 years, while the mean age of patients with benign lesions was $48.8 \pm 9.4$, ranging from 19 to 74 years.

In the group A (patients up to 50) there were $69(46.6 \%)$ patients. Of these, 21 $(30.4 \%)$ patients had breast cancer and 48 $(69.6 \%)$ of them had benign lesions. The ultrasound sensitivity in the group under 50 years was $33.3 \%$ higher than the mammographic sensitivity. In this group the ultrasound sensitivity was significantly higher than the mammographic sensitivity $(\mathrm{p}=0.045, \chi 2=4)$. The specificity of ultrasound was $12.5 \%$ higher than mammographic but the difference in the specificities of the two imaging tests was not statistically significant $(\mathrm{p}=0.24, \chi 2=1.39)$. Combining the two methods, high sensitivity of $90.5 \%$ was achieved, which was $4.8 \%$ higher compared to the sensitivity of ultrasound alone, and $38.1 \%$ higher compared to the sensitivity of mammography alone. The overall specificity of the two methods was $12.5 \%$ lower than mammographic specificity alone, and $25 \%$ lower relative to ultrasound specificity alone (Table 1).

In group B (patients 50-years and older) there were $79(53.4 \%)$ patients. Of these, $42(53.2 \%)$ patients had breast cancer and 37 (46.8\%) of them benign lesions. The ultrasound sensitivity was $4.7 \%$ higher than mammographic sensitivity, while the specificity of ultrasound was $16.2 \%$ higher than mammography. In this group the difference in the sensitivities of the two imaging tests was not statistically significant $\mathrm{p}=0.68$ $\left(\chi^{2}=0.17\right)$. Also, the difference in the specificities of the two imaging tests was not statistically significant $\mathrm{p}=0.15\left(\chi^{2}=2.08\right)$. Combining the two imaging tests, $100 \%$ sensitivity was achieved, but the overall specificity was $8.1 \%$ lower relative to the specificity of mammography, and $24.3 \%$ lower relative to specificity of ultrasound (Table 2).

In the group consisting of all patients, the sensitivity of ultrasound was statistically significantly higher relative to the sensitivity of mammography $\mathrm{p}=0.04\left(\chi^{2}=4.27\right)$. The higher specificity of ultrasound relative to mammographic was noted, also $\mathrm{p}=0.04\left(\chi^{2}=4\right)$. Combining the two methods high sensitivity (96.8\%) was achieved, but the overall speci-

Table 1 Individual and overall sensitivity and specificity of ultrasound and mammography in women under 50 years

\begin{tabular}{llll}
\hline \multirow{2}{*}{ Reliability } & \multicolumn{2}{l}{ Diagnostic procedures } & \\
\cline { 2 - 4 } & Mammography & Ultrasound & $\begin{array}{l}\text { Mammography+ } \\
\text { Ultrasound }\end{array}$ \\
\hline Sensitivity (\%) & 52.4 & 85.7 & 90.5 \\
Specificity (\%) & 66.7 & 79.2 & 54.2 \\
Positive predictive value (\%) & 40.7 & 64.3 & 46.3 \\
Negative predictive value (\%) & 76.2 & 92.7 & 92.9 \\
Positive likelihood ratio & 1.6 & 4.1 & 2 \\
Negative likelihood ratio & 0.71 & 0.18 & 0.17 \\
\hline
\end{tabular}


Table 2 Individual and overall sensitivity and specificity of ultrasound and mammography in women 50 years and older

\begin{tabular}{llll}
\hline \multirow{2}{*}{ Reliability } & \multicolumn{2}{l}{ Diagnostic procedures } & \\
\cline { 2 - 4 } & Mammography & Ultrasound & $\begin{array}{l}\text { Mammography+ } \\
\text { Ultrasound }\end{array}$ \\
\hline Sensitivity (\%) & 90.5 & 95.2 & 100 \\
Specificity (\%) & 64.9 & 81.1 & 56.8 \\
Positive predictive value (\%) & 74.5 & 85.1 & 71.9 \\
Negative predictive value (\%) & 85.7 & 93.8 & 100 \\
Positive likelihood ratio & 2.6 & 5 & 2.3 \\
Negative likelihood ratio & 0.15 & 0.06 & - \\
\hline
\end{tabular}

Table 3 Individual and overall sensitivity and specificity of ultrasound and mammography in all 148 patients

\begin{tabular}{llll}
\hline \multirow{2}{*}{ Reliability } & \multicolumn{2}{l}{ Diagnostic procedures } \\
\cline { 2 - 4 } & Mammography & Ultrasound & $\begin{array}{l}\text { Mammography+ } \\
\text { Ultrasound }\end{array}$ \\
\hline Sensitivity (\%) & 77.8 & 92.1 & 96.8 \\
Specificity (\%) & 65.9 & 80 & 55.3 \\
Positive predictive value (\%) & 62.8 & 77.3 & 61.6 \\
Negative predictive value (\%) & 80 & 93.2 & 95.9 \\
Positive likelihood ratio & 2.3 & 4.6 & 2.2 \\
Negative likelihood ratio & 0.34 & 0.1 & 0.06 \\
\hline
\end{tabular}

Table 4 Sensitivity of ultrasound and mammography in 63 patients with breast cancer

\begin{tabular}{llll}
\hline \multirow{2}{*}{ Mammography } & \multicolumn{2}{l}{ Ultrasound } & \\
\cline { 2 - 4 } & Positive $(\mathrm{n} ; \%)$ & Negative $(\mathrm{n} ; \%)$ & Total $(\mathrm{n} ; \%)$ \\
\hline Positive $(\mathrm{n} ; \%)$ & $46(73)$ & $3.7)$ & $49(77.8)$ \\
Negative $(\mathrm{n} ; \%)$ & $12(19.1)$ & $2(3.2)$ & $14(22.2)$ \\
Total $(\mathrm{n} ; \%)$ & $58(92.1)$ & $5(7.9)$ & $63(100)$ \\
\hline
\end{tabular}

ficity was lower than the specificity of each method separately. Thus, the overall specificity was $10.6 \%$ lower than the specificity of mammography, and even $24.7 \%$ lower than the specificity of the ultrasound (Table 3 ).

Table 4 shows that, of all breast cancers, $19.1 \%$ were correctly identified as cancer by ultrasound but not by mammography, while $4.7 \%$ of all cancers were correctly identified as cancer by mammography, but not by ultrasound. Combining the two methods, in which case the finding is considered positive if both or either test is positive, in two cases (3.2\%) the finding was false negative.

\section{Discussion}

Since there is no factor that prevents breast cancer, like other cancers, the only possible way to reduce mortality is early detection of breast cancer.

Mammography is currently the only breast imaging modality that is widely used for the screening, while ultrasound is a wide- 
ly used imaging technique in the diagnosis of mammographic detected or palpable lesions $(3,5)$. The sensitivity and specificity of mammography in breast cancer diagnosis is variable and depends primarily on the age of the patient and breast density (6).

Considering the age of the patients in most published studies, the higher sensitivity and specificity of mammography at 50 years and over has been shown compared to women aged from 40 to $49(7,8,9)$.

Sibbering and al. (8) compared the sensitivity but not the specificity of mammography in women aged from 50 to 70 (257 women) and women under 50 years of age (143 women). The sensitivity of the mammography in the first group was $83 \%$, and in the second, $65 \%(\mathrm{p}=0.001)$.

The higher sensitivity of mammography in women aged over 50 was proven in research conducted by Ciatto and al. (7) and by Dixon and al. (9). In these studies, similar to Sibbering's study, the sensitivity of mammography was analysed, but not the sensitivity of the ultrasound.

In our study, the sensitivity of mammography was $38.1 \%$ higher in women 50 years and older in relation to women under 50 years, which is in accordance with published results $(7,8,9)$.

Houssami and al. (10) proved that for women younger than 50 years, the sensitivity of ultrasound and mammography in relation to age has little variability, but the sensitivity of mammography increases substantially after age 50 . Their study also showed that the difference between the specificities of these two methods is small and age does not have any important influence on the specificity of the methods.

Devolli-Disha and al. (11) showed the higher accuracy of ultrasound than mammography in symptomatic women below 45 years as well the fact that the sensitivity of mammography progressively increases after 60 years.
In our study, in the group of women younger than 50 , the sensitivity of ultrasound was significantly higher $(33.3 \%)$ in relation to mammography, while in women over 50 years, this difference was only $4.7 \%$, which is in accordance with published results.

In 1977, Teixidor and al. (12) published a study about the individual and combined sensitivity of these two methods. The study involved 200 patients and 30 of them had breast cancer. The sensitivity of mammography was $94 \%$, sensitivity of ultrasound $78 \%$, while the combined sensitivity was $97 \%$.

The higher sensitivity of mammography in relation to ultrasound was shown by Negri and al. (13). Combining the two methods, they achieved overall sensitivity equal to the sensitivity of mammography (89\%) while overall specificity was only $46 \%$.

In the study conducted by Moss and al. (14) the sensitivity of ultrasound was $88.9 \%$ and mammography $78.9 \%$. Combining the two methods, overall sensitivity was $94.2 \%$, but overall specificity was only $67.9 \%$ as before.

The significantly higher sensitivity of ultrasound in relation to mammography was shown by Rotten and Levaillant (15). In their study specificity values were not published.

Housami and al. (16) conducted research on a group of patients aged from 25-55 years. Combining ultrasound and mammography, they achieved sensitivity of $76.3 \%$ and even $100 \%$ specificity, which is a difference from other studies.

Devolli-Disha and al. (11) proved in their study that ultrasound is a $20.5 \%$ more sensitive and $14.6 \%$ more specific method in relation to mammography.

In our study, combining the two methods high sensitivity of $96.8 \%$ was achieved, while specificity decreased to $55.3 \%$, which is in accordance with the results of most of the studies above.

When mammography and ultrasound are combined, the possibility that breast 
cancer will be misdiagnosed is $2.4 \%$ according to most results $(11,13-18)$. Devolli et al. (11) in their study correctly identified $25.1 \%$ of all breast cancers by ultrasound but not by mammography, while $4.6 \%$ of all cancers were correctly diagnosed by mammography but not by ultrasound, which is similar to our results (Table 4). In our study we had 3.2\% misdiagnosed cancers, which means that both methods were negative in only two cases. This result is in accordance with the results of other studies (11-18) which indicates the importance of combining ultrasound and mammography in order to reduce the number of undetected breast cancers to a minimum.

\section{Conclusion}

In breast cancer diagnosis, in women under the age of 50, ultrasound is a significantly more sensitive imaging test than mammography, but in women over 50 years the sensitivity of both imaging tests is almost equal. The combination of ultrasound and mammography achieves high sensitivity so the number of undetected breast cancers is reduced to a minimum, but specificity is decreased.

Authors' contributions: Conception and design: SM; Acquisition, analysis and interpretation of data: SM and MB; Drafting the article: SM, GS and JMM; Revising it critically for important intellectual content: $\mathrm{SM}$ and $\mathrm{MB}$.

Conflict of interest: The authors declare that they have no conflict of interest. This study was not sponsored by any external organisation.

\section{References}

1. McPherson K, Steel M, Dixon J. Breast cancerepidemiology, risk factors, and genetic. Brit Med J. 2000;321:624-8.

2. Jemal A, Tivvari RC, Murrav T, Ghafoor A, Samuels A, Ward E, et al. Cancer statistics. CA Cancer J Clin. 2004;54(1)8-29.
3. Goldner B, Dodić M, Mijović Z, Stević R. Klinički ultrazvuk u bolestima dojke. Beograd: Medicinski fakultet Beograd; 1998. p. 15-153.

4. American College of Radiology. Illustrated Breast Imaging Reporting and Data System (BI-RADS) 3rd ed. Reston, Va: American College of Radiology; 1998.

5. Boris B, Renata HK. - prevod s engleskog Leksikon ACR BI-RADS, mamografija. Branko Š (ur.), ACR-BIRADS Postupci oslikavanja dojki i sustav tumačenja i kategorizacija nalaza; Oslikavanje dojki - Atlas mamografija Utrazvuk; 2006.

6. Kerlikowske K, Grady D, Barclay J, Sickles EA, Ernster V. Effect of age, breast density, and family history on the sensitivity of first screening mammography. JAMA. 1996;276:33-8.

7. Ciatto S, Rosselli del Turco M, Catarzi S, Morrone D. The contribution of ultrasonography to the differential diagnosis of breast cancer. Neoplasma. 1994;41:341-5.

8. Sibbering DM, Burrell HC, Evans EJ, Yeoman LJ, Wilson ARM, Robertson JF, et al. Mammographic sensitivity in women under 50 years presenting symptomatically with breast cancer. The Breast. 1999;4:127-9.

9. Dixon JM, Anderson TJ, Lamb J, Nixon SJ, Forrest APM. Fine needle aspiration cytology, in relationships to clinical examination and mammography in the diagnosis of a solid breast mass. Br J Surg. 1986;71:593-6.

10. Housami N, Irvvig L, Simpson M, McKessar M, Blome S, Noakes J. Comparative sensitivity and specificity of mammography in young women with simptoms. AJR Am J Roentgenol. 2003;180:935-45.

11. Devolli-Disha E, Manxhuka-Kërliu S, Ymeri H, Kutllovci A. Comparative accuracy of mammography and ultrasound in women with breast symptoms according to age and breast density. Bosn J Basic Med Sci. 2009;9(2):131-6.

12. Teixidor H S, Kazam E. Combined mammographic \pm sonographic evaluation of breast masses. Am J Roentgenol. 1977;409-17.

13. Negri S, Bonetti F, Capitanio A, Bonzanini M. Preoperative diagnostic accuracy of fine-needle aspiration in the management of breast lesions: comparison of specificity and sensitivity with clinical examination, mammography, echography, and thermography in 249 patients. Diagn Cytopathol. 1994;11:4-8.

14. Moss HA, Britton PD, Flower CDR, Freeman AH, Lomas DJ, Warren RML. How reliable is modern breast imaging in differentiating benign from malignant breast lesions in the symptomatic population? Clin Radiol. 1999;54:676-82. 
15. Rotten D, Levaillant J M. The value of ultrasonic examination to detect and diagnose breast carcinomas. Analysis of the results obtained in 125 tumors using radiographic and ultrasound mammography. Ultrasound Obstet Gynecol. 1992;2:203-14.

16. Houssami N, Irwig L, Loy C. Accuracy of combined breast imaging in young women. Breast. 2002;11:36-40.
17. Zonderland HM, Coerkamp EG, Hermans J, van de Vijver MJ, van Voorthuisen AE. Diagnosis of breast cancer: contribution of US as an adjunct to mammography. Radiology. 1999;213:413-22.

18. Rahbar G, Sie AC, Hansen GC, Prince JS, Melany $\mathrm{ML}$, Reynolds $\mathrm{HE}$ et al. Benign versus malignant solid breast masses: US differentiation. Radiology. 1999;213:889-94. 